\title{
Zeta Potentials of Magnetite Particles and Alloy 690 Surfaces in Alkaline Solutions
}

\author{
Ji-Min Lee ${ }^{1}$, , Dong-Seok $\operatorname{Lim}^{1,2}$, Soon-Hyeok Jeon ${ }^{1}(\mathbb{D})$ and Do Haeng Hur ${ }^{1, *(D)}$ \\ 1 Materials Safety Technology Development Division, Korea Atomic Energy Research Institute, 989-111, \\ Deadeok-Daero, Yuseong-gu, Daejeon 34057, Korea; jmlee0915@kaeri.re.kr (J.-M.L.); \\ limds@kaeri.re.kr (D.-S.L.); junsoon@kaeri.re.kr (S.-H.J.) \\ 2 Department of Materials Science and Engineering, Chungnam National University, 99, Daehak-ro, \\ Yuseong-gu, Daejeon 34134, Korea \\ * Correspondence: dhhur@kaeri.re.kr; Tel.: +82-42-868-8388; Fax: +82-42-868-8696
}

Received: 11 August 2020; Accepted: 8 September 2020; Published: 9 September 2020

\begin{abstract}
Magnetite particles deposited on the secondary side of a steam generator (SG) can degrade the integrity and performance of pressurized water reactors. Therefore, it is necessary to produce the data of fundamental interfacial electrokinetic properties of magnetite particles and SG tube materials. This study investigated the zeta potentials of magnetite nanoparticles and Alloy 690 surfaces, which were dependent on the $\mathrm{pH}$ value, $\mathrm{pH}$ agent, and the presence of $\mathrm{NaCl}$. The zeta potentials of the magnetite nanoparticles increased in the negative direction as the $\mathrm{pH}$ increased, regardless of the $\mathrm{pH}$ agent. At the same $\mathrm{pH}$ value, the absolute values of the zeta potentials with different $\mathrm{pH}$ agents were: ethanolamine $<$ ammonia $<$ morpholine. In the presence of $\mathrm{NaCl}$, the zeta potentials of the particles further increased negatively. The meaning of the measured zeta potentials was discussed in terms of the dispersion stability and the agglomeration of the particles. Based on the relationship between the zeta potentials of the particles and Alloy 690 surfaces, the magnetite deposition on Alloy 690 was also discussed. Furthermore, the empirical formulas for the $\mathrm{pH}$-dependent zeta potentials of magnetite particles in each alkaline solution were suggested.
\end{abstract}

Keywords: zeta potential; magnetite; Alloy 690; steam generator; water chemistry; pH; $\mathrm{pH}$ agent; $\mathrm{NaCl}$

\section{Introduction}

Corrosion products of carbon steel and other structural materials in pressurized water reactors (PWRs) are released to the secondary water as a result of flow-accelerated corrosion [1,2]. These corrosion product particles are transported to steam generators (SGs) and attached to SG tubes to form deposits with a porous structure. The majority of these deposits are composed of magnetite [3]. These magnetite deposits reduce the heat transfer efficiency, hinder the normal water flow, accelerate the corrosion of the SG tube materials owing to the galvanic effect, and even act as a site where aggressive impurities can accumulate [4-6]. Therefore, mitigating and inhibiting such magnetite deposition is a key to controlling the chemistry of secondary water for reliable PWR operation.

To achieve this goal, it is essential to produce fundamental dispersion property data of magnetite particles suspended in secondary water. The degree of dispersion stability of colloidal particles in an aqueous solution can be evaluated by determining the zeta potential, which is the principal electrokinetic property of the particles and governs their agglomeration, dispersion, and deposition on metal surfaces $[7,8]$. The degree of zeta potential is typically measured in $\mathrm{mV}$ and determines the degree of electrostatic repulsion between adjacent particles. For example, as the zeta potential approaches zero, the particles tend to agglomerate; however, the repulsive force of each particle increases as the zeta potential increases, thereby increasing the dispersion stability in the solution. On the other hand, 
like particles in suspension, any metal surface in an aqueous environment can acquire a zeta potential. Accordingly, the metal surface can interact with the adjacent charged particles. Recent studies have demonstrated that the number of particles deposited on a metal surface is strongly affected by the difference in the zeta potentials of the particles and metal surfaces $[9,10]$. Therefore, comparing the zeta potentials of magnetite particles and SG tube materials could prove useful for studying magnetite deposition behavior in the secondary side of SGs.

The secondary side of PWRs is managed by a thorough $\mathrm{pH}$ control to suppress the corrosion of the structural materials of the secondary system. In general, the $\mathrm{pH}$ has been controlled to approximately 9.0-10.0 with ammonia, morpholine, or ethanolamine (ETA), which are the most widely used pH control agents. Although the zeta potential data of magnetite particles in the PWRs are critical, numerous previous studies have only reported the zeta potentials of magnetite particles in alkaline solutions using $\mathrm{NaOH}$ or $\mathrm{KOH}$, which are not used in the nuclear industry. In addition, $\mathrm{NaCl}$, which can be introduced to secondary water by condenser in-leakage, can cause stress corrosion cracking or pitting corrosion of SG tubes [11,12]; therefore, its concentration has been strictly regulated less than $5 \mathrm{ppb}$ for $\mathrm{Na}$ and $10 \mathrm{ppb}$ for $\mathrm{Cl}$, based on the water chemistry guideline values during SG operation $[13,14]$. However, few studies have been conducted on how $\mathrm{NaCl}$ affects the zeta potential of magnetite particles in nuclear water chemistry. Furthermore, a literature survey showed that there have been few studies on the surface zeta potential of SG tube materials in secondary water.

Thus, in this study, when the $\mathrm{pH}$ was controlled with ammonia, morpholine, or ETA, the $\mathrm{pH}$-dependent zeta potentials of magnetite nanoparticles were measured and compared. The effect of the addition of $\mathrm{NaCl}$ on the zeta potential of magnetite nanoparticles was also investigated. Accordingly, the meaning of the measured zeta potentials was qualitatively discussed in terms of the dispersion stability and the agglomeration of the particles. Additionally, the surface zeta potentials of Ni-based thermally treated Alloy 690 were measured, which is the primary SG tube material used in PWRs because of its excellent corrosion resistance. Subsequently, the magnetite deposition on Alloy 690 was discussed by comparing the measured zeta potentials of magnetite particles and Alloy 690 surfaces.

\section{Experimental}

\subsection{Zeta Potential Measurement}

Figure 1 shows a schematic of the zeta potential measurement using a Zetasizer (Nano ZS90) equipped with an automatic pH-titrator (MPT-2) (Malvern Panalytical Ltd., Worcestershire, UK). Initially, we prepared a sample solution by dispersing magnetite nanoparticles in deionized water at a concentration of $25 \mathrm{mg} / \mathrm{L}$. The magnetite nanoparticles were purchased from Sigma-Aldrich Co. (St. Louis, MO, USA), whose size ranged from $4 \mathrm{~nm}$ to $6 \mathrm{~nm}$ with an average of $5 \mathrm{~nm}$. Additionally, a diluted alkaline solution of ammonia, morpholine, or ETA was prepared. The basic properties of these three $\mathrm{pH}$ agents used in this study are presented in Table 1. Subsequently, the alkaline solution was injected into the sample solution using a programmable micrometering pump, and the $\mathrm{pH}$ of the sample was titrated in real-time. Afterwards, when the $\mathrm{pH}$ reached the target value, the sample was automatically transferred to the zeta potential measurement cell. After the stabilization time, the electric field was applied through an electrode pair mounted on both sides of the cell. The charged magnetite particles were then attracted toward the oppositely charged electrode with a velocity proportional to the field strength and charge. The electrophoretic mobility of the particles was measured by the electrophoretic light scattering (ELS) technique that is known as the most suitable method for determining the zeta potential of particles fine enough to stay suspended in a solution [7]. The measured mobility was then converted to the zeta potential $(\zeta)$ through Henry's equation [15] expressed as:

$$
\zeta=\frac{\eta U_{E}}{\varepsilon_{r} \varepsilon_{0} f(\kappa a)}
$$




$$
f(\kappa a)=\frac{2}{3}\left[1+\frac{1}{2\left(1+\frac{2.5}{\kappa a\{1+2 \exp (-\kappa a)\}}\right)^{3}}\right]
$$

where $\eta$ is the viscosity of the solution, $U_{E}$ is the electrophoretic mobility, $\varepsilon_{r}$ is the relative permittivity of the solution, $\varepsilon_{0}$ is the permittivity of vacuum, $f(\kappa a)$ is the Henry's function for a spherical colloidal particle of radius $a$, and $\kappa$ is the reciprocal of the Debye length. In this study, $\kappa a$ was assumed to be sufficiently large; therefore, the $f(\kappa a)$ value was set to 1 . The refractive index and absorption of the magnetite particles were set to 2.420 and 0.01 , respectively. The principle for measuring the zeta potential is presented in detail [16]. After the measurement was finished, the solution in the cell was automatically transferred back to the sample container. The zeta potential measurements were automatically repeated from the second step by increasing the $\mathrm{pH}$ value from 9.0 to 10.0. No acid solution was used during the test. The magnetite nanoparticles remained thermodynamically stable during the zeta potential measurements in this study.

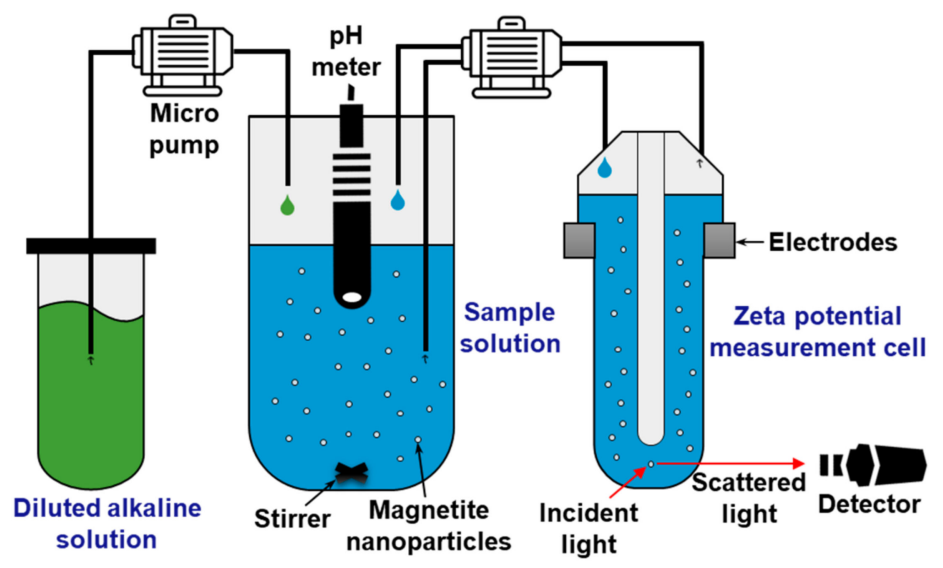

Figure 1. Schematic of zeta potential measurement setup using an automatic $\mathrm{pH}$ titration system.

Furthermore, to compare the zeta potential of magnetite nanoparticles with and without the addition of $\mathrm{NaCl}$, we prepared an additional sample solution by dispersing the magnetite nanoparticles with an average size of $5 \mathrm{~nm}$ in deionized water at a concentration of $25 \mathrm{mg} / \mathrm{L}$. High-purity $\mathrm{NaCl}$ $(99.99 \%)$ was added to the solution at a concentration of $6.6 \mathrm{mg} / \mathrm{L}$. The $\mathrm{pH}$ of the solution was automatically titrated from 9.0 to 10.0 with diluted ETA. The test procedure was the same as that described above, and all observations were carried out at $25^{\circ} \mathrm{C}$.

Table 1. Basic properties of three $\mathrm{pH}$ agents used in this study.

\begin{tabular}{ccccc}
\hline pH Control Agents & $\begin{array}{c}\text { Chemical } \\
\text { Formula }\end{array}$ & $\begin{array}{c}\text { Density } \\
\left(\mathbf{g} / \mathbf{c m}^{\mathbf{3}}\right)\end{array}$ & $\begin{array}{c}\text { Boiling Point } \\
\left({ }^{\circ} \mathbf{C}\right)\end{array}$ & $\begin{array}{c}\text { Molar Mass } \\
(\mathbf{g} / \mathbf{m o l})\end{array}$ \\
\hline Ammonia solution, 30\% & $\mathrm{NH}_{3}+\mathrm{H}_{2} \mathrm{O}$ & 0.89 & 36 & 17.0 \\
Morpholine & $\mathrm{C}_{4} \mathrm{H}_{9} \mathrm{NO}$ & 1.01 & 129 & 87.1 \\
Ethanolamine (ETA) & $\mathrm{C}_{2} \mathrm{H}_{7} \mathrm{NO}$ & 1.01 & 170 & 61.1 \\
\hline
\end{tabular}

\subsection{Surface Zeta Potential Measurement}

Particles in the suspension become charged and move under electrophoresis upon application of the electric field. Using these suspended particles as tracers, the surface zeta potential of metal can be estimated by measuring the electrophoretic mobility of the particles located at multiple distances from the metal surface.

Figure 2 shows a schematic of the surface zeta potential measurement kit. Initially, we prepared rectangular samples of Alloy 690, which were not larger than $5 \mathrm{~mm}$ (length) $\times 4 \mathrm{~mm}$ (width) $\times 1 \mathrm{~mm}$ 
(thickness). To minimize the effect of surface conditions on the zeta potential [10], the sample surfaces were carefully ground to obtain a similar roughness. The sample was then attached to a sample holder and immersed in a solution in a cuvette, as shown in Figure 2. The solution was the same as that used to measure the zeta potential of magnetite nanoparticles as described in Section 2.1, and the pH was either 9.0 or 10.0. When an electric field is applied through a pair of Pd electrodes, the electrophoresis of tracer particles begins. We measured the apparent tracer electrophoretic mobility at four different distances from the sample surface by rotating a screw for adjusting the sample height. The surface zeta potential of Alloy 690 was then derived by the linear extrapolation method. All data were obtained at $25^{\circ} \mathrm{C}$; additional details have been described elsewhere [17].

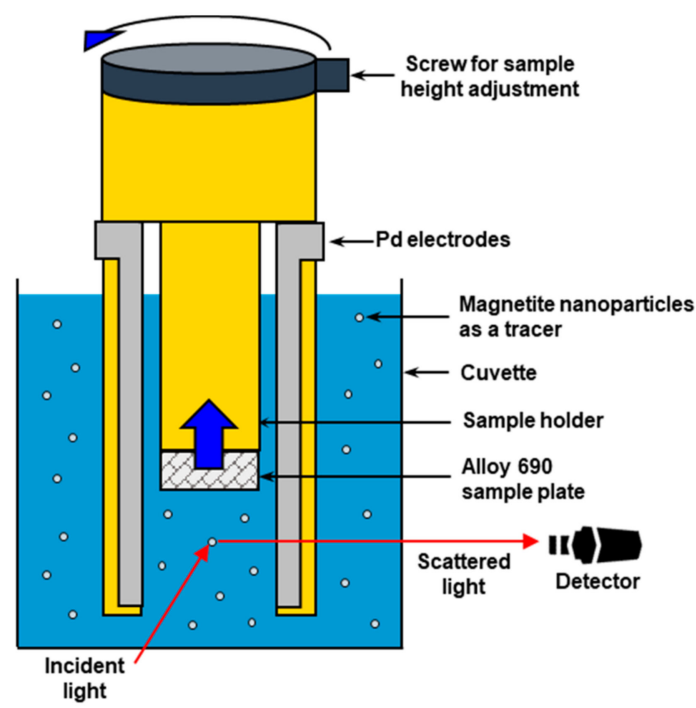

Figure 2. Schematic of a surface zeta potential measurement kit.

Furthermore, surface zeta potential measurements using Alloy 690 were conducted to compare the results obtained with and without the addition of $\mathrm{NaCl}$. The concentrations of magnetite particles and $\mathrm{NaCl}$ in the solution were the same as those of the solution used to measure the zeta potential, as described in Section 2.1. The $\mathrm{pH}$ was maintained at 9.5, with diluted ETA. The test procedure was the same as that mentioned above.

\section{Results and Discussion}

\subsection{Effect of $\mathrm{pH}$ Control Agents}

Figure 3 shows the zeta potentials of magnetite nanoparticles as a function of $\mathrm{pH}$ value that is controlled with the addition of ETA, ammonia, or morpholine at $25^{\circ} \mathrm{C}$. According to previous studies, the zeta potential is dependent on the solution $\mathrm{pH}$, and the relationship between zeta potential and $\mathrm{pH}$ is empirically expressed as [18,19]:

$$
\zeta=k(\mathrm{IEP}-\mathrm{pH})
$$

where $k$ is a constant, and IEP is the isoelectric point, i.e., the $\mathrm{pH}$ value at which the zeta potential is equal to zero. In general, the zeta potential decreases as the $\mathrm{pH}$ increases. A decrease in the negative zeta potential to a more negative value implies greater repulsion to a negatively charged surface or particle [19]. The solid lines in Figure 3 show the linear regression fits of the measured zeta potentials 
in the solution of each $\mathrm{pH}$ agent based on Equation (3). The $\mathrm{pH}$-dependent zeta potentials of magnetite nanoparticles at $25^{\circ} \mathrm{C}$ can be expressed by the following empirical equations:

$$
\begin{gathered}
\zeta_{E}=-9.0 \times \mathrm{pH}+57.5\left(\mathrm{R}^{2}=0.81\right) \\
\zeta_{A}=-10.2 \times \mathrm{pH}+61.9\left(\mathrm{R}^{2}=0.81\right) \\
\zeta_{M}=-12.3 \times \mathrm{pH}+77.8\left(\mathrm{R}^{2}=0.93\right)
\end{gathered}
$$

where $\zeta_{E}, \zeta_{A}$, and $\zeta_{M}$ are for the solutions of ETA, ammonia, and morpholine, respectively. These equations are valid at $\mathrm{pH}$ values ranging from 9.0 to 10.0. In the future, if these equations are further upgraded by reflecting the effects of variables such as temperature, particle size, and shape, it is expected to be used in various ways as basic interfacial properties of magnetite particles suspended in secondary water. As shown in Figure 3, the magnetite nanoparticles were negatively charged under all conditions. Regardless of the $\mathrm{pH}$ agent, when the $\mathrm{pH}$ value increased from 9.0 to 10.0, the zeta potentials of the particles increased in the negative direction, which seems because the activity of hydroxyl groups $\left(\mathrm{OH}^{-}\right)$increases with increasing $\mathrm{pH}$ value. This result implies that as the $\mathrm{pH}$ increases, the repulsive force between the particles increases, leading to an increase in dispersion stability and a decrease in the agglomeration. In addition, the zeta potential of the particles varied depending on the $\mathrm{pH}$ agent. At the same $\mathrm{pH}$ value, the absolute value of the zeta potential was the lowest when using ETA and the highest when using morpholine. According to a previous investigation [20], the electrical conductance of the magnetite column in the solutions increased in the order: ETA $<$ ammonia $<$ morpholine. This result implies that electrical properties of the particles vary depending on which solutions the particles are dispersed in; therefore, it is thought that the zeta potential of the particles appears to be high in the morpholine solution because the electrical conductance of the particles increases. Unfortunately, exactly what mechanism causes the zeta potential to be different depending on $\mathrm{pH}$ agent was not found in the literature. In fact, there are few studies comparable to our results with the exception of one previous investigation by Essi et al. [21]. They reported that the zeta potentials of magnetite were approximately $-16 \mathrm{mV},-25 \mathrm{mV}$, and $-36 \mathrm{mV}$ when the $\mathrm{pH}$ was controlled at 9.2 with ETA, ammonia, and morpholine, respectively [21]. According to our results using Equation (4), the zeta potentials were calculated to be $-25.3 \mathrm{mV},-32.0 \mathrm{mV}$, and $-35.4 \mathrm{mV}$ when the $\mathrm{pH}$ was 9.2 for the solutions of ETA, ammonia, and morpholine, respectively. The results for morpholine were almost similar, but the results for ETA and ammonia were evaluated to be greater in absolute values than those in the literature [21]. These differences may be caused by that the zeta potentials were measured by the streaming potential technique with a magnetite column made of $500 \mathrm{~nm}$-sized magnetite powders in the previous study, whereas the zeta potentials were measured by the ELS technique with $5 \mathrm{~nm}$-sized magnetite nanoparticles dispersed in the solutions in this study. On the other hand, based on the zeta potential results in this study, it is expected that the size of the magnetite particles should be the largest in the case of ETA, followed by ammonia and morpholine. This is because the lower the absolute value of zeta potential, the greater the tendency of particles to agglomerate.

Figure 4 shows the relationship between the zeta potentials of magnetite nanoparticles and Alloy 690 surfaces at $\mathrm{pH}$ values of 9.0 and 10.0, depending on the $\mathrm{pH}$ agent, at $25^{\circ} \mathrm{C}$. For all cases, the magnetite nanoparticles and Alloy 690 surfaces were negatively charged, thereby indicating that a repulsive force exists between them. As shown in Figure 4, the differences in the zeta potentials between the magnetite nanoparticles and Alloy 690 surfaces $(\triangle \mathrm{ZP})$ could be calculated. When the $\mathrm{pH}$ increased from 9.0 to 10.0, $\Delta \mathrm{ZP}$ increased regardless of the $\mathrm{pH}$ agent. Furthermore, $\Delta \mathrm{ZP}$ indicates the electrostatic repulsive force between the particles and Alloy 690 surfaces; hence, the greater the $\Delta \mathrm{ZP}$, the more is the energy required to attach the particles to the surfaces. Accordingly, it is expected that the amount of magnetite deposition on the Alloy 690 surfaces will decrease as the $\mathrm{pH}$ increases from 9.0 to 10.0, regardless of the $\mathrm{pH}$ agent. In addition, at the same $\mathrm{pH}$ value, $\Delta \mathrm{ZP}$ was the smallest in the ETA solution and the largest in the ammonia solution. Consequently, it is expected that the number of magnetite deposits will be the highest in ETA and the lowest in ammonia solution. However, the deposition behavior on the hot surface of operating SG tubes may not be fully explained by our 
results because the zeta potentials in this study were all measured at $25^{\circ} \mathrm{C}$. Nevertheless, considerable recent efforts have been made to improve this approach for a reliable description of the deposition behavior, along with the zeta potential measurement $[9,10]$.

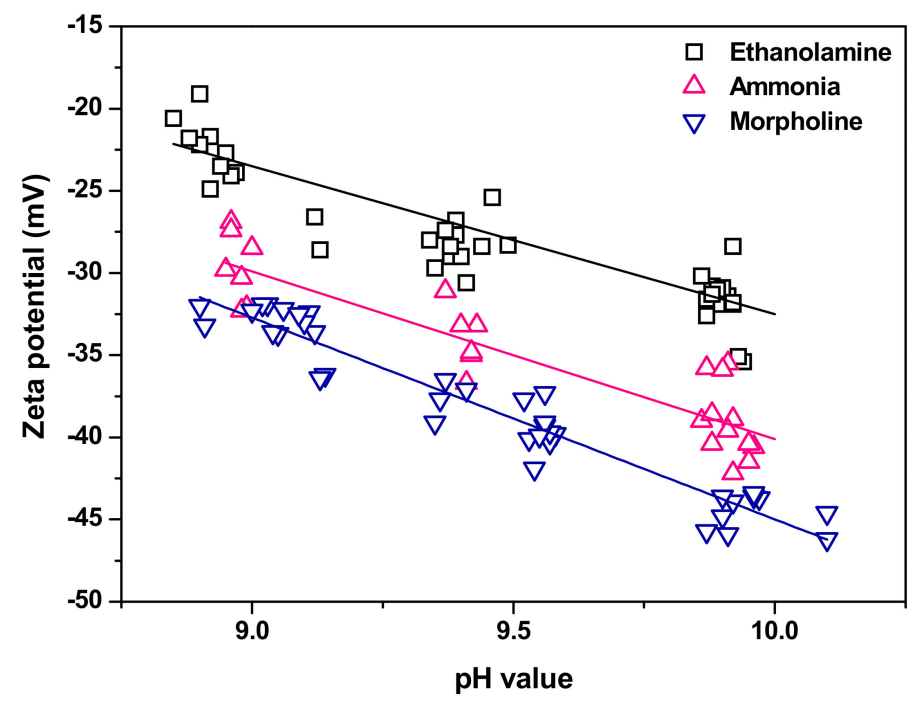

Figure 3. Zeta potentials of magnetite nanoparticles as a function of $\mathrm{pH}$ value, controlled with ethanolamine (ETA), ammonia, or morpholine at $25^{\circ} \mathrm{C}$.

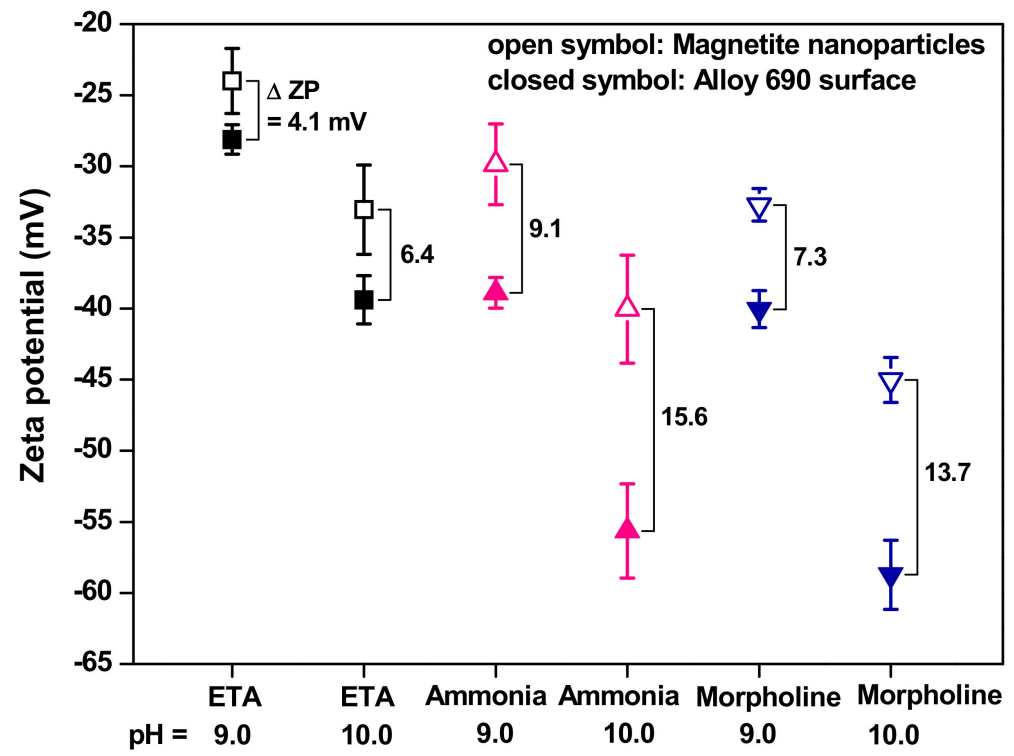

Figure 4. Relationship between the zeta potentials of magnetite nanoparticles and Alloy 690 surfaces at a $\mathrm{pH}$ of 9.0 and 10.0 , depending on the $\mathrm{pH}$ agent at $25^{\circ} \mathrm{C}$.

\subsection{Effect of $\mathrm{NaCl}$ Addition}

Figure 5 shows the effect of the addition of $\mathrm{NaCl}$ on the zeta potential of magnetite nanoparticles in solutions with $\mathrm{pH}$ values adjusted with ETA at $25^{\circ} \mathrm{C}$. As shown in the figure, even when $\mathrm{NaCl}$ was added, the magnetite particles were negatively charged, and the zeta potential increased further in the negative direction. Moreover, the zeta potential of the magnetite nanoparticles increased negatively as the $\mathrm{pH}$ increased from 9.0 to 10.0. Accordingly, the addition of $\mathrm{NaCl}$ increases the repulsive forces between the colloidal magnetite particles, thereby increasing the dispersion stability. Therefore, it is also expected that the agglomeration of the particles will be suppressed, which is also supported by 
the previous experimental results where the size of synthesized magnetite nanoparticles was found to decrease with increasing $\mathrm{NaCl}$ concentration [22].

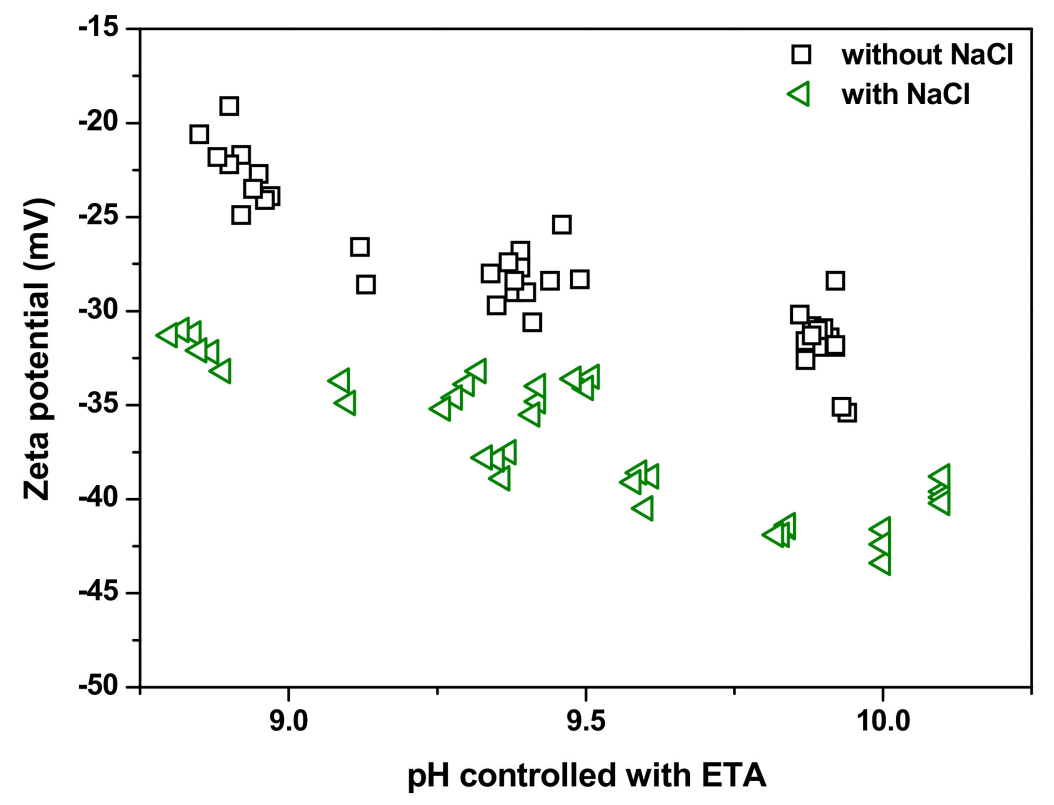

Figure 5. Zeta potentials of magnetite nanoparticles in solutions with and without $\mathrm{NaCl}$ addition as a function of $\mathrm{pH}$ value, controlled with ETA at $25^{\circ} \mathrm{C}$.

Figure 6 shows the relationship between the zeta potential of magnetite nanoparticles and the Alloy 690 surfaces at a $\mathrm{pH}$ of 9.5 controlled with ETA at $25^{\circ} \mathrm{C}$. The particles and surfaces were all negatively charged and the zeta potentials increased in the negative direction with the addition of $\mathrm{NaCl}$. As shown in the figure, $\triangle \mathrm{ZP}$ was calculated to be $5.1 \mathrm{mV}$ and $15.9 \mathrm{mV}$ without and with $\mathrm{NaCl}$ addition, respectively. These results indicate that the repulsive force between the particles and Alloy 690 surfaces increases with the addition of $\mathrm{NaCl}$. Therefore, it is predicted that the deposition of magnetite particles on Alloy 690 surfaces requires more energy, leading to a decrease in the number of magnetite deposits owing to the presence of $\mathrm{NaCl}$.

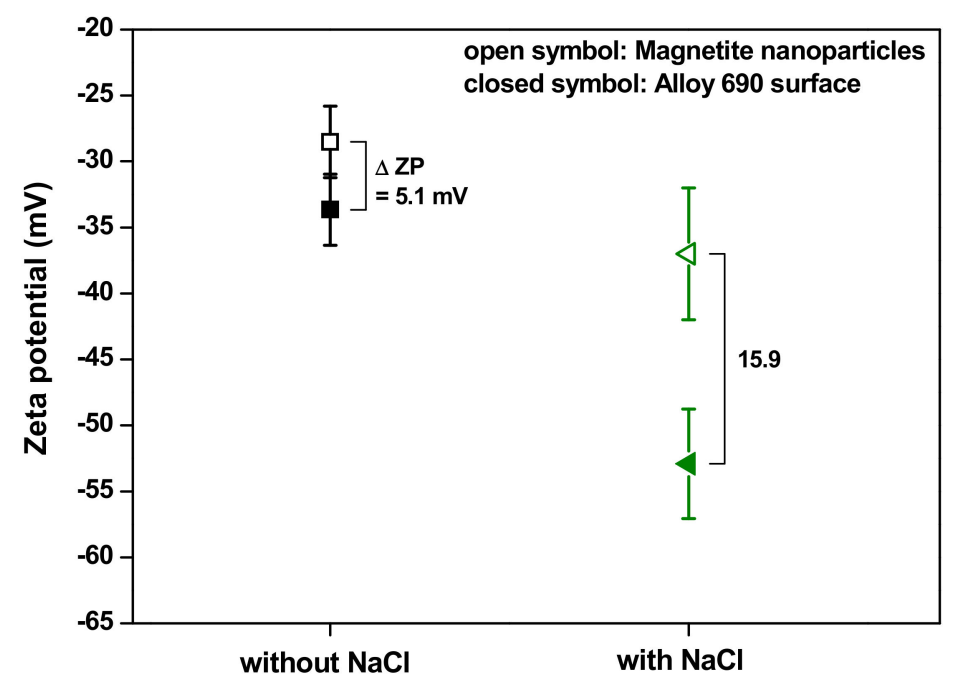

Figure 6. Relationship between the zeta potentials of magnetite nanoparticles and Alloy 690 surfaces at a pH of 9.5, controlled with ETA at $25^{\circ} \mathrm{C}$. 


\section{Conclusions}

The zeta potentials of magnetite nanoparticles and Alloy 690 surfaces were measured at $25^{\circ} \mathrm{C}$. Based on the experimental results, the following conclusions were drawn:

1. The empirical formulas for the zeta potentials of magnetite nanoparticles derived in the $\mathrm{pH}$ range from 9.0 to 10.0 at $25^{\circ} \mathrm{C}$ were as follows: $\zeta_{E}=-9.0 \times \mathrm{pH}+57.5$ for ETA; $\zeta_{A}=-10.2 \times \mathrm{pH}+61.9$ for ammonia; $\zeta_{M}=-12.3 \times \mathrm{pH}+77.8$ for morpholine.

2. The zeta potentials of the magnetite nanoparticles increased in the negative direction as the $\mathrm{pH}$ increased from 9.0 to 10.0 , regardless of the $\mathrm{pH}$ agent. This result indicates that as the $\mathrm{pH}$ increases, the repulsive force between the particles increases, thereby leading to an increase in the dispersion stability. At the same $\mathrm{pH}$ value, the absolute value of the zeta potential increased in the order: ETA < ammonia < morpholine, meaning that the dispersion stability of the particles also increases in the same order.

3. The difference in the zeta potentials between the magnetite nanoparticles and Alloy 690 surfaces increased with increasing $\mathrm{pH}$ from 9.0 to 10.0, regardless of the $\mathrm{pH}$ agent. At the same $\mathrm{pH}$ value, the difference was the largest in ammonia. From these results, it is expected that the amount of magnetite deposited on the Alloy 690 surfaces will decrease as the $\mathrm{pH}$ increases from 9.0 to 10.0, and will be the smallest in the ammonia.

4. The zeta potentials of magnetite nanoparticles increased in the negative direction by the addition of $\mathrm{NaCl}$. In addition, the difference in the zeta potentials between the magnetite nanoparticles and Alloy 690 surfaces increased by approximately three times by the addition of $\mathrm{NaCl}$. These results suggest that $\mathrm{NaCl}$ plays a role in increasing the repulsive force between the particles and Alloy 690 surfaces.

Author Contributions: Conceptualization, S.-H.J. and D.H.H.; methodology, J.-M.L.; software, D.-S.L.; investigation, J.-M.L. and S.-H.J.; writing—original draft preparation, J.-M.L.; writing—review and editing, J.-M.L. and D.H.H.; supervision, D.H.H. All authors have read and agreed to the published version of the manuscript.

Funding: This work was supported by the National Research Foundation (NRF) grant funded by the government of the Republic of Korea (NRF-2017M2A8A4015159).

Conflicts of Interest: The authors declare no conflict of interest.

\section{References}

1. Marks, C. Steam Generator Management Program: Effects of Different $p H$ Control Agents on Pressurized Water Reactor Plant Systems and Components; Electric Power Research Institute (EPRI): Palo Alto, CA, USA, 2009.

2. Turner, C.W.; Khumsa-Ang, K. Corrosion product transport and fouling in nuclear steam generators. In Steam Generators for Nuclear Power Plants; Woodhead Publishing: Cambridge, UK, 2017; Chapter 9.

3. Jeon, S.-H.; Hong, S.; Kwon, H.-C.; Hur, D.H. Characteristics of steam generator tube deposits in an operating pressurized water reactor. J. Nucl. Mater. 2018, 507, 371-380. [CrossRef]

4. Jeon, S.-H.; Song, G.D.; Hur, D.H. Micro-Galvanic corrosion of steam generator materials within pores of magnetite flakes in alkaline solutions. Metals 2018, 8, 899. [CrossRef]

5. Turner, C.W.; Huang, M.; McKay, A. Hideout, hideout return and crevice chemistry in nuclear steam generators. In Steam Generators for Nuclear Power Plants; Woodhead Publishing: Cambridge, UK, 2017; Chapter 10.

6. Wolfe, R. Steam Generator Management Program: Steam Generator Deposit Removal Strategies Sourcebook; Electric Power Research Institute (EPRI): Palo Alto, CA, USA, 2015.

7. Carlson, J.J.; Kawatra, S.K. Factors affecting zeta potential of iron oxides. Miner. Process. Extr. Metall. 2013, 34, 269-303. [CrossRef]

8. Vidojkovic, S.M.; Rakin, M.P. Surface properties of magnetite in high temperature aqueous electrolyte solutions: A review. Adv. Colloid Interface Sci. 2017, 245, 108-129. [CrossRef] [PubMed]

9. Lee, J.-M.; Jeon, S.-H.; Kim, K.-S.; Han, J.; Hur, D.H. Effects of pH control agents on magnetite deposition on steam generator tubes. Ann. Nucl. Energy 2020, 143, 107486. [CrossRef] 
10. Shim, H.-S.; Park, M.-S.; Baek, S.H.; Hur, D.H. Effect of aluminum oxide coated on fuel cladding surface on crud deposition in simulated PWR primary water. Ann. Nucl. Energy 2018, 121, 607-614. [CrossRef]

11. Bahn, C.B.; Kasza, K.E.; Park, J.; Shack, W.J. Experimental simulation of $\mathrm{Na}$ and $\mathrm{Cl}$ hideout in steam generator crevices. Nucl. Eng. Des. 2012, 250, 156-166. [CrossRef]

12. Paine, J.P.N. Steam Generator Reference Book, Revision 1; Electric Power Research Institute (EPRI): Palo Alto, CA, USA, 1994; Volume 1.

13. Fruzzetti, K. Pressurized Water Reactor Secondary Water Chemistry Guidelines-Revision 8; Electric Power Research Institute (EPRI): Palo Alto, CA, USA, 2017.

14. Kawamura, H.; Shoda, Y.; Terachi, T.; Katsumura, Y.; Uchida, S.; Mizuno, T.; Muroya, Y.; Tsuzuki, Y.; Umehara, R.; Hirano, H.; et al. PWR secondary water chemistry guidelines in Japan-Purpose and technical background. Prog. Nucl. Energy 2019, 114, 121-137. [CrossRef]

15. Ohshima, H. Zeta potential. In Encyclopedia of Colloid and Interface Science; Tadros, T., Ed.; Springer: Berlin/Heidelberg, Germany, 2013. [CrossRef]

16. Kaszuba, M.; Corbett, J.; Watson, F.M.; Jones, A. High-concentration zeta potential measurements using light-scattering techniques. Phil. Trans. R. Soc. A 2010, 368, 4439-4451. [CrossRef] [PubMed]

17. Corbett, J.C.W.; McNeil-Watson, F.; Jack, R.O.; Howarth, M. Measuring surface zeta potential using phase analysis light scattering in a simple dip cell arrangement. Colloids Surf. A Physicochem. Eng. Asp. 2012, 396, 169-176. [CrossRef]

18. Fruzzetti, K. Multivariable Assessment of Flow Accelerated Corrosion and Steam Generator Fouling, Literature Review; Electric Power Research Institute (EPRI): Palo Alto, CA, USA, 2003.

19. Varrin, R., Jr. Characterization of PWR Steam Generator Deposits; Electric Power Research Institute (EPRI): Palo Alto, CA, USA, 1996.

20. Essi, J. The Effect of Temperature on the Zeta Potential of Magnetite Particles in Ammonia, Morpholine and Ethanolamine Solutions. Master's Thesis, Aalto University, Espoo, Finland, 2013.

21. Essi, J.; Konsta, S.; Timo, S. Determining Zeta Potential of Magnetite Particles in PWR Secondary Side Water Treated with Ammonia or Ethanolamine by Using Streaming Potential Technique. In Proceedings of the 20th NPC International Conference, Brighton, UK, 2-7 October 2016; p. 151.

22. Park, J.Y.; Patel, D.; Choi, E.S.; Baek, M.J.; Chang, Y.; Kim, T.J.; Lee, G.H. Salt effects on the physical properties of magnetite nanoparticles synthesized at different $\mathrm{NaCl}$ concentrations. Colloids Surf. A Physicochem. Eng. Asp. 2010, 367, 41-46. [CrossRef] 